\title{
Incorporating analytical research experience into the undergraduate curriculum
}

\author{
Kevin B. Thurbide ${ }^{1}$
}

Published online: 24 June 2016

(C) Springer-Verlag Berlin Heidelberg 2016

\section{Introduction}

Chemistry is inherently a laboratory-based discipline. Even historically, where instructors often exclusively demonstrated chemical phenomena to the class, the value and need for students to carry out their own experiments was clearly recognized [1]. As such, practical laboratory work is frequently included as an established part of many modern university chemistry programs [1].

Over the years, student enrollment on many campuses has increased significantly and, at least here in Canada, it is expected to continue along this trajectory and rise $14 \%$ by 2020 [2]. As a result, class sizes have increased considerably in undergraduate chemistry courses, which lead to little personal interaction between instructors and students, and can inhibit new and even traditional elements of instruction [3]. Further, this also greatly impacts the ability of programs to provide laboratory experience to students since the facilities, materials, and staffing requirements for this are increasingly very expensive to maintain [1].

Different approaches have evolved in response to such enrollment pressure over the last couple of decades. For example, many programs have invoked some form of computerassisted laboratory teaching to accommodate increasing student numbers [1]. However, this can unfortunately reduce the amount of direct practical chemistry experience that students acquire, and can adversely influence their perception of laboratory work, which can be quite negative [1]. As a result,

Kevin B. Thurbide

thurbide@ucalgary.ca

1 Department of Chemistry, University of Calgary, Calgary, AB T2N 1N4, Canada

chemical educators are continually advocating for more engaging, active learning environments for students, even in large enrollment courses [4]. Since practical skills have long been a hallmark of solid training for chemical analysts, it follows that laboratory experience in the teaching of analytical chemistry also remains critical. Therefore, universities can further benefit from exploring new ways of providing practical and engaging laboratory work for analytical students.

Here, we briefly describe our experience with a new course started 4 years ago at the University of Calgary entitled "Chemistry 402: Introduction to Research in Chemistry." The course is aimed at providing a relatively simple route for students to acquire practical and interesting experience in research as part of their undergraduate degree. In view of this, the following discusses how this course can be beneficial in offering chemistry students an engaging and relevant exposure to analytical research and practical laboratory work.

\section{Context for creating the course}

Traditionally, analytical laboratory exposure was relatively moderate in our program. For example, we offer three halfcredit courses (i.e., one semester each) in analytical chemistry. Chemistry 311 is introductory and primarily titration-oriented, whereas Chemistry 315 and 515, respectively, offer introductory and advanced looks at analytical instrumentation. Each operates a laboratory component for $4 \mathrm{~h}$ per week during the semester and provides students with a brief exposure to a variety of analytical procedures/methods. Although these are reasonably effective and comprise a significant portion of the student's grade (i.e., $\sim 35 \%$ ), there remain considerable amounts of lecture-based assignments and exams that must also be maintained. This renders little time for instructors to focus on laboratory teaching, and often leaves students 
overwhelmed with the workload and less able to engage in the experimental side of the course.

Of greater practical relevance, we also offer a full-credit course (i.e., two semesters) for more senior students called Chemistry 502: Research in Chemistry. This course has students join a research group in the department to undertake a project, and it is designed to give them a complete exposure to the chemistry research process. Of note, in the initial phase, students must strike an advisory committee, investigate the background of their project, and produce a written proposal and literature review (10\% of grade). Then, half-way through the course, they must prepare a presentation of their progress and answer questions from their committee ( $20 \%$ of grade). At the end, they must also prepare a formal written report ( $25 \%$ of grade) and deliver an oral presentation $(20 \%$ of grade) of their final results. The balance is research work ( $25 \%$ of grade) that is conducted between these milestones throughout the year. Accordingly, this course acts essentially as a senior-level undergraduate thesis research class.

Chemistry 502 has operated successfully for many years and provided numerous students with a solid exposure to all aspects of the research process in general. However, we noted over the past decade or more that enrollment in this course was steadily declining. For instance, Fig. 1 shows the number of students registered in the course each year from 2000 to 2011. As seen, we typically used to have 30 to 35 students take the course annually, which was reasonably consistent with the number of chemistry majors in our program. However, after 2003, this enrollment began to decrease yearly. In fact, it was reduced $85 \%$ by about 2010 . Over the same period though, our program enrollment numbers fluctuated by less than $3 \%$. Therefore, it appeared that something was wrong, and in 2011 we began to further investigate the issue.

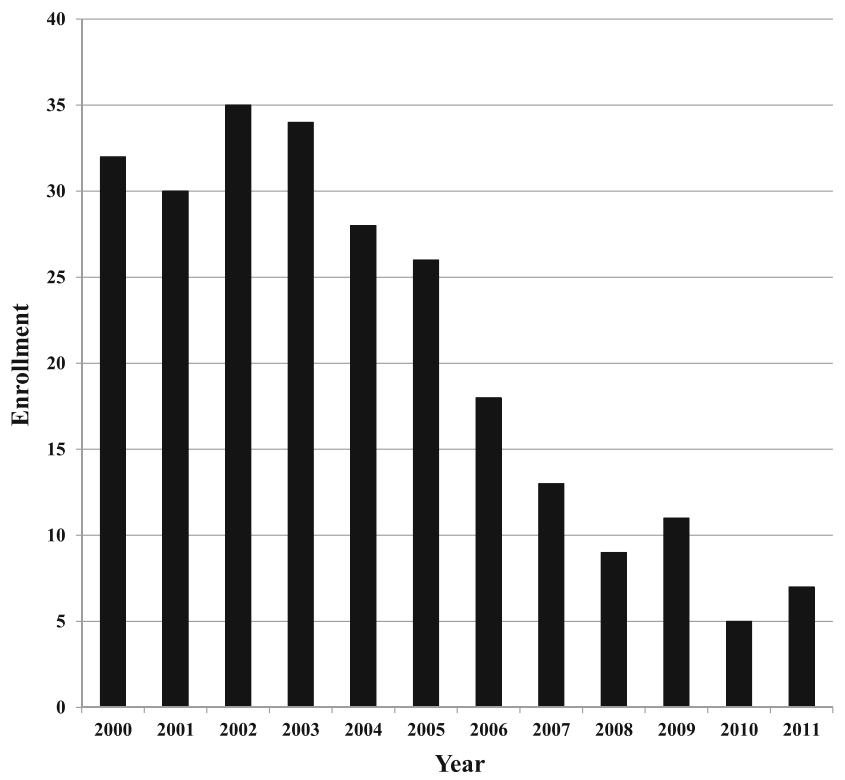

Fig. 1 Student enrollment in Chemistry 502 from 2000 to 2011
From surveying students in our program about this, several clear themes emerged as potential problems. First, students were uncertain if they could handle the workload of Chemistry 502, and all of its deliverables, especially while they were maintaining a full load of other senior-level courses. Secondly, they were unsure of whether they would be good at research and feared not being able to learn how to properly perform it. Finally, they were also quite uncertain of whether or not they would like doing research and were not comfortable committing to a full-year course in order to find out. Since these concerns were prevalent among students, we set out to address them.

\section{A new undergraduate research option}

The primary solution raised was to create a new type of research-oriented course. To address concerns over the fear of committing to such a course, it was agreed that this new endeavor should be a half-credit course, where the hours involved would equal those expected of a typical lab/lecture load (i.e., $7-8 \mathrm{~h} / \mathrm{wk}$ ). Inherent to this, it was overwhelmingly decided that this was not to become a 'mini Chemistry 502' course. Rather, this was to be more fundamentally geared towards having students directly involved in aspects of chemical research and inquiry/exploration that are often not possible in the classroom. The dominant focus was on having students experience research as much as possible, while spending less time on other sundry course requirements. In this way, the new course would have a heavy accent towards the mechanics of discovery and the environment of a working chemist. Finally, to make it accessible to as many people as possible, the course was to be open to all students and faculty members (both research and instructor stream). To support this, the only prerequisites for the course are mutual consent between the student and faculty member (i.e., no GPA restriction to enroll), and completion of one half-credit in general chemistry to help foster these connections. As such, the course is open to those within their first year of program and onward. Note that GPA here refers to "Grade Point Average" and is used at our institution to reflect the student's mean performance in all of their courses to date. Students could also repeat the course for credit once if desired. Given these criteria, the new Chemistry 402 course began.

With respect to grading, it was decided that a general scheme would be applied to the course, and individual research supervisors would then be responsible for assigning tasks and grades within that framework. For, instance, Chemistry 402 is divided into two categories for rating performance. One-half of the grade comes from "Research Work," and the other comes from "Presentation." The specific items and weighting therein depend entirely on the supervisor in the context of the project. For example, depending on the individuals involved, the research aspect may be broken down 
into things such as effort, troubleshooting, skill, or results as appropriate. Conversely, presentation might involve items like weekly discussions, a brief summary written report, or an oral/poster presentation. Rather than mandate these milestones for all projects, they are chosen and tailored between the student and supervisor to best support the work. Conversely though, students are required to have some form of midterm examination in order to receive formal feedback on how they are doing. For this, many supervisors simply employ a brief oral exam of the student's knowledge of their project. The final total percentage is then converted to a letter grade using a common scale applied to all students in the course.

There have been a number of different ways that Chemistry 402 projects have manifested themselves. These include traditional projects in research labs, literature searches on topics of interest, development of teaching tools and/or laboratory revisions, performing calculations and data processing, setting up and calibrating instrumentation, generating starting materials in support of larger projects, reproducing earlier findings for proof, and many more. In all, the main theme is to get students maximum exposure to the laboratory environment while building their independence and confidence in that setting.

\section{Analytical research in Chemistry 402}

Since the course began, our own analytical research laboratory has hosted many Chemistry 402 students and we have found it to have a very positive impact on their overall view and understanding of the research environment. Our interests are primarily in separation science and so, many projects involved chromatography, detection, or sample preparation. In all cases, the students had independent projects where we worked with them to help guide the effort. Students normally found a full day or more a week that they dedicated to the course by working in the laboratory. We initially trained them on the technology being used for the first few weeks, which involved them in assembling the apparatus, troubleshooting problems, and characterizing the instrument once operating. Then they would begin exploring the unknown parameter that comprised their project (e.g., new type of column or detector). We would also have weekly update meetings to go over the previous week's progress and define goals for the coming week.

Regarding other aspects, half-way through the semester we would have a 20 min oral midterm exam to quiz them on their project, results to date, and objectives. At the end of the course, the students would submit a very brief report (nominally five pages) with the main observations highlighted and any applicable data. This was normally given in a basic bulleted format to make for clear reading and simple assembly. The students also gave a short 10 - to 15 - min overview presentation of this report to our laboratory research group and answered questions. So, in all, this approach provided an atmosphere where the bulk of their course time was spent exploring at the bench. Some projects even led to student co-authored articles $[5,6]$.

\section{An analytical case study}

In order to gauge how Chemistry 402 might be impacting the analytical undergraduate experience in our program, we embarked on a brief study of student perceptions. Specifically, a short questionnaire was given to students in our instrumentation oriented laboratories (i.e., Chemistry 315 and 515) and also those in Chemistry 402. Since most of our own student projects were focused on experiments involving gas chromatography (GC), we solicited the survey responses immediately after the students had finished the GC modules in Chemistry 315 and 515, and after they had completed their GC-based Chemistry 402 project. The questions were designed to probe their general comfort level with GC in terms of knowledge and technical confidence. The results are shown in Table 1.

From looking at the data, several things can be noted. First, the junior undergraduates in Chemistry 315 are overall less confident in GC than those senior students in Chemistry 515, as would be anticipated. This is indicated by their relatively higher scores (i.e., less sure) and greater uncertainty in the overall assessment. Second, the most confident responses from the Chemistry 315 and 515 students appeared for questions 2 and 5, which are particularly geared toward the theory of GC and how to utilize GC data. As such, it indicates that they feel reasonably confident in what they are receiving in lecture on GC. However, by comparison, the Chemistry 402 students were notably more confident (and to nearly an equivalent level) for all of the questions posed. Since questions 1, 3, and 4 are aimed more at a technical understanding of GC, this can be interpreted as having acquired a greater comfort level with both the theory and practice of the method, based on their experience in Chemistry 402.

This is further supported by commentary also received on the questionnaire. For example, Chemistry 315 and 515 students felt that they needed more hands-on experience to better prepare for using GC. Comments like "I didn't really learn much; we just injected and printed data" or "I think I could operate GC with guidelines, but I don't think I could troubleshoot a problem" reinforce this. One undergrad even noted that he/she wanted to learn practical things like how to change a carrier gas cylinder. In contrast to this, Chemistry 402 students generally felt that they had more time to explore, practice, and fail without the pressure of a typical $4 \mathrm{~h}$ 'recipebased' laboratory. One of the most telling comments in this regard came from a first year student: "This course has left me with a very good understanding of GC. It is amazing how at the beginning of the semester I was very intimidated by the technique and now I feel comfortable enough to build, fix, and work with a GC system." 
Table 1 Chemistry Student Survey Upon Completing the Course GC module

\begin{tabular}{llll}
\hline Question $^{\mathrm{a}}$ & $\begin{array}{l}\text { Chem } \\
402\end{array}$ & $\begin{array}{l}\text { Chem } \\
515\end{array}$ & $\begin{array}{l}\text { Chem } \\
315\end{array}$ \\
\hline $\begin{array}{l}\text { 1. Based on your experience now, do you think you could operate a GC } \\
\text { in industry if assuming a new job tomorrow that requires you to do so? }\end{array}$ & $1.1 \pm 0.2$ & $2.0 \pm 0.0$ & $2.7 \pm 1.4$ \\
$\begin{array}{l}\text { 2. Do you now have a good understanding of how GC is done and what } \\
\text { it is good for? }\end{array}$ & $1.2 \pm 0.3$ & $1.0 \pm 0.0$ & $2.3 \pm 1.5$ \\
$\begin{array}{l}\text { 3. Could you now troubleshoot a problem with a GC that was not working } \\
\text { properly? }\end{array}$ & $1.1 \pm 0.2$ & $3.8 \pm 0.8$ & $3.7 \pm 1.4$ \\
$\begin{array}{l}\text { 4. Could you now explain how to build a working GC from some simple, } \\
\text { basic parts? }\end{array}$ & $1.3 \pm 0.5$ & $2.3 \pm 1.1$ & $3.9 \pm 1.4$ \\
$\begin{array}{l}\text { 5. Could you now interpret and utilize GC data that someone else gave you } \\
\text { to work with? }\end{array}$ & $1.2 \pm 0.3$ & $1.2 \pm 0.4$ & $2.0 \pm 1.4$ \\
\hline
\end{tabular}

${ }^{\text {a }}$ Response range from 1 to $5: 1=$ Yes, $2=$ Maybe, $3=$ Not sure, $4=$ Probably not, $5=$ No.

Uncertainty is given as the standard deviation of the collective responses.

\section{The outcome}

Overall then, the implementation of Chemistry 402 in our program has been very positive for our undergraduate students, both analytical and otherwise. Students generally feel more prepared, less pressured, and more engaged in learning what a chemist does. In analytical areas, it gives them very practical exposure to working with instrumentation, troubleshooting, and applications. This positive feedback is also being detected in student interest in the course. For example, Fig. 2 shows the enrollment statistics for Chemistry 402 since its inception in 2012. As seen, after its first year, enrollment jumped significantly and has been steadily increasing ever since. In fact, given its rapid popularity, some colleagues have expressed concern that it will drain students from Chemistry 502 and deplete that course. However, it appears that the opposite may be happening. Also included in Fig. 2 is the

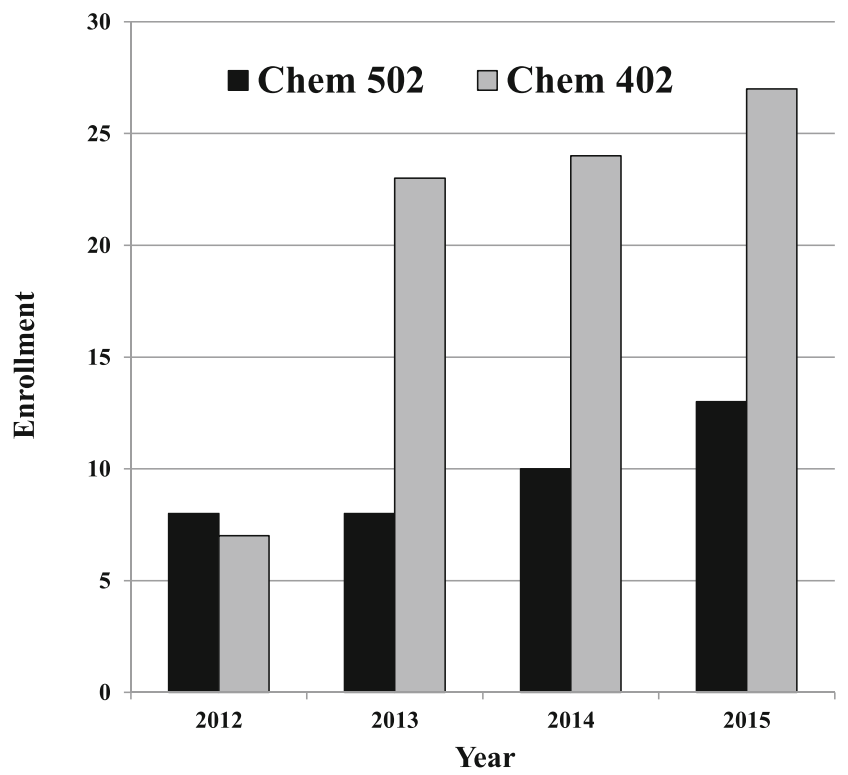

Fig. 2 Student enrollment in Chemistry 502 (black) and Chemistry 402 (grey) from 2012 to 2015 enrollment numbers for Chemistry 502 over this same period. As shown, there is an uptick in the number of students opting for Chemistry 502 now and this course is experiencing its first steady enrollment increase in over a decade. This indicates that Chemistry 402 may in fact be helping students get over their fear of the unknown and motivating them to move more deeply into rigorous research. This certainly also seems to be the case with respect to how Chemistry 402 students are shaping their future. For example, over the period shown in Fig. 2, $45 \%$ of Chemistry 402 students went on to enroll in graduate studies in chemistry, while $33 \%$ moved on to professional schools and $22 \%$ finished and pursued employment.

Finally, with respect to the relative interest in the course across our program, it appears that a significant portion of junior undergraduates are opting for it. For example, conventionally, Chemistry 502 is normally taken by students in their senior undergraduate year as a capstone course in research experience. However, analysis of Chemistry 402 registrants to date indicates that approximately 4.4, 13.2, 39.6, and $42.8 \%$ of the students enrolled in the course have been in their 1st, 2nd, 3rd, and 4th year of program, respectively. Therefore, although the current tendency is still towards more senior students, more than half of those who took the course were in their 1st to 3rd y of program. Therefore, with the option to engage in research now being open to more junior students (even those in their 1st year of program), many are expressing an interest. This trend could very well continue as we further actively promote the course, which is currently achieved by announcing it in lectures, broadcasting it through our undergraduate chemistry club, displaying it on our website, and encouraging students to recommend it to one another.

Given these outcomes, our general program perception of Chemistry 402 is quite positive and many faculty members are now embracing this opportunity to have students experience chemistry in a more direct and simple way. For analytical undergraduate students, such a practical exposure to working with essential laboratory tools, methods, and troubleshooting is 
exceptionally valuable. Accordingly, we believe it can help better inform such students not only on what a career analytical chemist does, but also if they would actually enjoy doing that.

Acknowledgments The author gratefully acknowledges Dr. Andrea Scott and Dr. Jill Murakami for assisting in the survey distribution, and also Grace Whitehead and Jin Meng for their help in acquiring enrollment statistics.

\section{References}

1. Reid N, Shah I. Chem Educ Res Pract. 2007;8:172-85.

2. Charbonneau L in University Affairs Magazine, May 26 (2011)

3. Cooper M. J Chem Ed. 1993;70:476-7.

4. Eichler JF, Peeples J. Chem Educ Res Pract. 2016;17:197-208.

5. Frantz JJ, Alkhateeb FL, Thurbide KB. Chromatography. 2015;2: 488-501.

6. Scott AF, Thurbide KB, Quickfall D. Can J Chem. 2015;93:784-9.

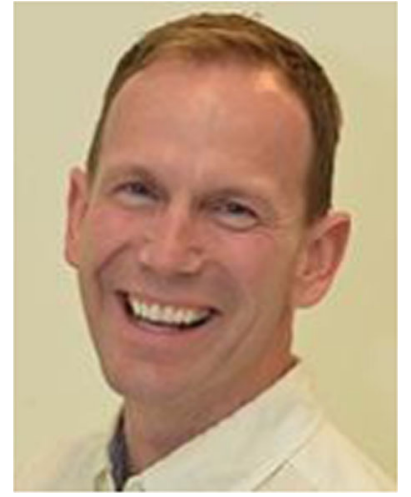

Kevin Thurbide is originally from Alberta, Canada. He received his BSc (Hon. Chem.) from St. Mary's University in Halifax, Nova Scotia in 1990. $\mathrm{He}$ then received his $\mathrm{PhD}$ in Analytical Chemistry from Dalhousie University (Halifax) in 1995 under the supervision of Dr. Walter Aue. In 1996 he took up a research position with the Pulp and Paper Research Institute of Canada in Montreal, Quebec, which was also jointly held with the Pulp and Paper Research Centre at McGill University. In January 2000, he joined the faculty at the University of Calgary, where he is currently a Professor in the Chemistry Department, Associate Head, and the Director of Graduate Studies. His research concentrates on analytical separations and focuses on developing sample preparation, chromatography, and detection methods for the analysis of trace organic compounds present in complex samples of interest to a variety of industrial sectors. 